\title{
COMPORTAMENTO DA LARANJEIRA 'VALÊNCIA' SOBRE SEIS PORTA-ENXERTOS NO NOROESTE DO PARANÁ ${ }^{1}$
}

\author{
PEDRO ANTONIO MARTINS AULER ${ }^{2}$, ANA CRISTINA GRADE FIORI-TUTIDA ${ }^{3}$, ZULEIDE HISSANO TAZIMA ${ }^{4}$
}

RESUMO - Com o objetivo de identificar alternativas ao uso do limoeiro 'Cravo', avaliou-se a influência de porta-enxertos na produtividade e nas características físico-químicas dos frutos de laranjeira 'Valência' em experimento instalado em janeiro de 1994, sem irrigação, no município de Nova Esperança-PR. Adotou-se delineamento experimental em blocos ao acaso, com quatro repetições, três plantas úteis por parcela e seis porta-enxertos como tratamentos: limoeiro 'Cravo' $(C$. limonia), tangerineira 'Cleópatra' ( $C$. reshni) e 'Sunki' (C. sunki), citrangeiro 'Troyer' (P. trifoliata x C. sinensis), tangeleiro 'Orlando' (C. tangerina $\mathrm{x} C$. paradisi) $\mathrm{e}$ laranjeira 'Caipira' (C. sinensis). Avaliou-se a qualidade dos frutos em duas safras (2002 e 2005), o desenvolvimento vegetativo e a eficiência de produção em 1999 e 2003, e a produção (1996 a 2005). Em relação ao ‘Cravo', a 'Sunki' induziu maior produção e volume de copa, e eficiência de produção e qualidade do fruto equivalentes; o 'Troyer' induziu eficiência de produção equivalente, frutos com rendimento industrial superior e peso médio inferior; a 'Cleópatra' induziu produção equivalente, eficiência de produção inferior e maior volume de copa. O estudo mostrou que os porta-enxertos 'Sunki', 'Cleópatra' e 'Troyer' se destacaram como opções para a diversificação do 'Cravo'.

Termos para indexação: Citrus sinensis, qualidade de frutos, arenito Caiuá.

\section{BEHAVIOR OF' 'VALENCIA' ORANGE TREE ON SIX ROOTSTOCKS IN THE NORTHWEST OF PARANA STATE}

\begin{abstract}
In order to identify alternatives to the utilization of 'Rangpur' lime, the major rootstock cultivar used in citrus orchards, an experiment was conducted in a field established in 1994 in Nova Esperança, Paraná, Brazil and maintained without irrigation. Six rootstock cultivars were tested in relation to yield and physico-chemical characteristics of 'Valencia" fruits: 'Rangpur'lime $(C$. limonia), 'Cleopatra' (C. reshni) and 'Sunki' (C. sunki) mandarins, 'Troyer' citrange (P. trifoliata $\mathrm{x}$ C. sinensis), 'Orlando' tangelo ( $C$. tangerina $\mathrm{x} C$. paradisi) and 'Caipira' orange (C. sinensis). The complete randomized block design was used with four replications and three useful trees per plot. Fruit quality was evaluated in 2002 and 2005, growth development and yield efficiency in 1999 and 2003, and yield from 1996 until 2005. Compared to 'Rangpur', the 'Sunki' rootstock induced higher yield and canopy volume, and equivalent yield efficiency and fruit quality; the 'Troyer' rootstock induced the production of fruits with higher industrial yield, equivalent yield efficiency and lower average fruit weight; the 'Cleopatra' rootstock induced higher canopy volume, equivalent yield, and lower yield efficiency. The study showed that the rootstock 'Sunki', 'Cleopatra' and 'Troyer' can be valuable alternatives to 'Rangpur' lime rootstock utilization.
\end{abstract}

Index terms: Citrus sinensis, fruit quality, Caiuá sandstone.

\section{INTRODUÇÃO}

Em 2004, o Brasil produziu 18.313.717 toneladas de laranja, o equivalente a 415 milhões de caixas de 40,8 kg. O Paraná, onde o cultivo de laranja está em crescimento nas regiões norte e noroeste, participou com 2,17\% dessa produção (IBGE, 2004).

Dentre as variedades de laranja cultivadas no mundo, a laranja 'Valência' está entre as mais importantes. De maturação tardia, apreciada pelo seu elevado teor de suco, excelente sabor, aparência e coloração atraentes, é considerada a segunda cultivar mais plantada no Paraná. Sob o ponto de vista industrial, representa um dos suportes da agroindústria em todo o mundo, tendo em vista a excelente qualidade do suco para processamento, armazenamento e transporte (Coelho, 2002).

O porta-enxerto exerce uma influência direta sobre as copas na adaptação a diferentes condições edafoclimáticas, na tolerância às enfermidades virais ou fúngicas e nos níveis de produção e qualidade de fruta (Bravo \& Gallardo, 1994a). Sob as mesmas condições, alguns porta-enxertos se destacam em determinados aspectos (Schäfer et al., 2001) e, por esse motivo, sua adequada seleção é fundamental no êxito da atividade citrícola.

No Paraná, ainda é utilizado predominantemente o limoeiro 'Cravo' para todas as cultivares-copa, situação que, provavelmente, não atende às características peculiares de cada variedade, impedindo que a planta manifeste todo o seu potencial

\footnotetext{
${ }^{1}$ (Trabalho 045-07). Recebido em 28-02-2007. Aceito para publicação em: 20-07-2007.

${ }^{2}$ Eng. Agr., MSc., Pesquisador do Instituto Agronômico do Paraná. Paranavaí, PR. aulerpe@iapar.br.

${ }^{3}$ Eng $^{a}$. Agr. ${ }^{a}$, Dra., Pesquisadora do Instituto Agronômico do Paraná. Paranavaí, PR. ana_tutida@iapar.br.

${ }^{4}$ Eng $^{\mathrm{a}}$. Agr. ${ }^{\mathrm{a}}$, MSc, Pesquisadora do Instituto Agronômico do Paraná. Londrina, PR. zuleide@iapar.br.
} 
produtivo (Pompeu Jr. et al., 2002), além do risco que oferece em casos de enfermidades ou outros tipos de problemas que podem afetar certos porta-enxertos. É o caso do declínio, cuja incidência a partir da década de 1980, em plantas de laranjeiras-doces, enxertadas em limoeiro 'Cravo', estimulou a diversificação de porta-enxertos, sendo indicados como opções as tangerineiras 'Sunki' e 'Cleópatra', a laranjeira 'Caipira', o tangeleiro 'Orlando', além do citrumeleiro 'Swingle' (Donadio et al., 1993).

Mais recentemente, a morte súbita dos citros vem acometendo com grande gravidade copas enxertadas sobre os limoeiros 'Cravo' e 'Volkameriano', enquanto porta-enxertos como 'Cleópatra' e 'Sunki' têm-se mostrado tolerantes a esse problema (Müller et al., 2005).

Adicionalmente, as recomendações para diversificação de porta-enxertos devem estar baseadas em pesquisas regionais, pois estudos desenvolvidos nas condições edafoclimáticas do Paraná com certas variedades cítricas têm encontrado resultados diferentes daqueles obtidos em outras regiões citrícolas (Stenzel et al., 2005).

Assim, este trabalho teve como objetivo avaliar o comportamento produtivo, a qualidade do fruto e o desenvolvimento vegetativo da laranjeira 'Valência' sobre seis porta-exertos, na região noroeste do Estado, principal pólo de produção de laranja do Paraná.

\section{MATERIAL E MÉTODOS}

O experimento foi implantado em janeiro de 1994, em Latossolo Vermelho distrófico, textura média, localizado no terço inferior da pendente, no município de Nova Esperança-PR, com coordenadas de $23^{\circ} 10^{\prime} \mathrm{S}$ e $52^{\circ} 10^{\prime} \mathrm{W}$ e altitude de $582 \mathrm{~m}$. O clima da região é classificado como $\mathrm{Cfa}$, sem estação seca definida (Figura 1). O plantio foi realizado em camalhões, em espaçamento de 7 x $5 \mathrm{~m}$ (285 plantas/ha), sendo as plantas conduzidas sem irrigação e manejadas conforme recomendação técnica para o cultivo de citros (IAPAR, 1992).

Utilizou-se o delineamento experimental de blocos casualizados, com quatro repetições, três plantas úteis por parcela e, como tratamentos, seis porta-enxertos: limoeiro 'Cravo'(Citrus limonia Osbeck), tangerineiras 'Cleópatra' (Citrus reshni hort. ex Tanaka) e 'Sunki' (Citrus sunki hort. ex Tanaka), citrangeiro 'Troyer' [Poncirus trifoliata (L.) Raf. x Citrus sinensis (L.) Osbeck], tangeleiro 'Orlando' (Citrus tangerina hort. ex Tanaka $\mathrm{x}$ Citrus paradisi Macfad.) e laranjeira 'Caipira' [Citrus sinensis (L.) Osbeck]. Como variedade copa foi ytilizado o clone 'Valência 718', acesso IAPAR-94.

As colheitas das safras de 1996 a 2005 foram realizadas de setembro a novembro, tendo-se avaliado a produção por meio da pesagem total dos frutos das plantas úteis. A produção acumulada foi obtida pela soma da produção das safras individuais. A massa média do fruto foi obtida pela pesagem de uma amostra de 90 frutos. A produção acumulada relativa foi estimada para cada porta-enxerto, tendo como referência (100\%) o limoeiro 'Cravo'. Em avaliação realizada nos anos de 1999 e 2003 , foram obtidos, por meio de régua graduada, os dados relativos à altura das plantas (m) e diâmetro das copas (m), que foram utilizados para o cálculo do volume da copa $\left(\mathrm{m}^{3}\right)$, segundo Mendel (1956): $V=2 / 3 \pi R^{2} H$, onde $V$ é o volume $\left(\mathrm{m}^{3}\right)$; $R$ é o raio da copa (m), e H, a altura da planta (m). A eficiência da produção foi calculada dividindo-se o valor da produção pelo volume de copa.

$\mathrm{Na}$ avaliação da qualidade dos frutos, foram realizadas amostragens no mês de outubro de 2002 e 2005, coletando-se nove frutos/parcela, na posição mediana da copa. Foram avaliadas as seguintes variáveis: rendimento de suco em percentagem [(relação entre a massa do suco e a massa do fruto) x 100]; sólidos solúveis totais (SST), medidos em ${ }^{\circ}$ Brix, por meio de um refratômetro manual, com os valores corrigidos para $20^{\circ} \mathrm{C}$; acidez titulável total (ATT) por titulação, com NaOH a 0,1 N (AOAC, 1990), sendo os resultados expressos em porcentagem de ácido cítrico. Também foi estimado o ratio (SST/ATT) e calculado o rendimento industrial (RI), ou seja, o número de caixas/tonelada de suco concentrado, de acordo com a seguinte fórmula: $\mathrm{RI}=$ 660/IT (índice tecnológico), onde IT $=$ (rendimento de suco $\mathrm{x}$ sólidos solúveis totais $\mathrm{x} 40,8) / 10.000$, equivalente à quantidade de sólidos solúveis totais no suco $(\mathrm{kg})$, em uma caixa de colheita de frutos de 40,8 kg.

Em outubro de 2006, foi realizada avaliação visual para a determinação do percentual de sobrevivência das plantas, tendo em vista a possibilidade de ocorrência de declínio e outros problemas que podem afetar a combinação copa/porta-enxerto. Como não foi constatado nenhum sintoma visual, não houve necessidade de proceder a análises mais específicas para diagnóstico.

Os dados de produção transformados em $\sqrt{x+1}$ da safra de 1996 e os originais das variáveis de produção, desenvolvimento vegetativo e qualidade do fruto das demais safras avaliadas foram submetidos à análise de variância, complementada pelo de teste Tukey $(\mathrm{P} \leq 0,05)$.

\section{RESULTADOS E DISCUSSÃO}

Os maiores valores de massa média dos frutos foram observados em plantas enxertadas em tangeleiro 'Orlando', limoeiro 'Cravo' e laranjeira 'Caipira', seguidos das tangerineiras 'Cleópatra'e 'Sunki', tendo o citrangeiro 'Troyer' induzido o menor valor (Tabela 1). Não houve diferença entre os portaenxertos para os valores de rendimento de suco, acidez titulável e ratio. Entretanto, verificou-se que, com relação ao teor de sólidos solúveis, 'Troyer'e 'Caipira' apresentaram valores superiores ao 'Cravo', ficando os demais porta-enxertos numa faixa intermediária. Zekri \& Al-Jallel (2004) também constataram mais alta concentração de sólidos solúveis em frutos de laranjeira 'Valência' enxertada em citrangeiro 'Carrizo', quando comparada ao 'Cravo', que, neste caso, também não diferiu da 'Cleópatra' para sólidos solúveis e rendimento de suco.

Em relação ao rendimento industrial, 'Troyer' apresentou o melhor resultado, necessitando de menor quantidade de caixas de laranja para produzir uma tonelada de suco em relação ao 'Cravo' (Tabela 1), não diferindo dos demais porta-enxertos. O citrangeiro 'Troyer' induz ótima qualidade aos frutos das variedades nele enxertadas (Carlos et al., 1997). Stuchi et al. (2002) 
verificaram não haver diferenças entre os porta-enxertos 'Sunki', 'Cleópatra' e 'Troyer' em relação ao rendimento industrial, sólidos solúveis, acidez e ratio.

Os porta-enxertos induziram diferenças no desenvolvimento das copas de laranjeira 'Valência'. Aos cinco anos após o plantio, 'Cleópatra' induziu volume de copa equivalente a 'Sunki' e a 'Orlando', e superior aos demais. Aos nove anos, 'Cleópatra', 'Sunki' e 'Orlando' induziram maior volume de copa, superior a 'Cravo', 'Caipira' e 'Troyer' (Tabela 2). As menores alturas e diâmetros de copa foram observadas em 'Troyer', 'Cravo' e 'Caipira'. Para Sartori et al. (2002), a maior altura de plantas ocorreu quando a laranjeira 'Valência' foi enxertada em 'Caipira' e 'Sunki'. Ledo et al. (1999) verificaram que o maior volume de copa de laranjeira 'Valência 27' foi obtido sobre os porta-enxertos 'Cravo' e 'Cleópatra', e estes foram superiores à 'Sunki'. Pompeu Jr. et al. (2002) também constataram menor altura de planta e diâmetro de copa em laranjeiras 'Valência' enxertadas em citrangeiros 'Troyer' e 'Carrizo'. O vigor da variedade-copa é diretamente afetado pelo porta-enxerto, estando diretamente vinculado ao genótipo e suas relações. Dessa forma, a capacidade de um porta-enxerto vigoroso em absorver mais água e colocar a raiz em contato com os nutrientes propiciaria maior absorção destes, elevando os níveis nutricionais da planta e, conseqüentemente, aumentando o seu crescimento (Moreira, 1992; Vitti, 1992, citados por Schäfer et al., 2001).

Os porta-enxertos exerceram influência marcante sobre a produção de frutos, onde 'Sunki', 'Cleópatra', 'Orlando', 'Cravo', 'Troyer' e 'Caipira' induziram produções equivalentes ou superiores aos demais porta-enxertos, respectivamente, em nove, oito, oito, sete, cinco e três das dez safras avaliadas (Tabela 3). Quando se considera a produção acumulada das dez safras, a tangerineira 'Sunki' foi superior ao 'Cravo', 'Troyer' e 'Caipira', não diferindo da 'Cleópatra' e 'Orlando'. Essas diferenças entre os porta-enxertos representaram um acréscimo de 30,8\% para 'Sunki' e um decréscimo de $23,8 \%$ para 'Caipira', na produção acumulada de frutos relativa ao limoeiro 'Cravo' (Tabela 4). Tais resultados confirmam os obtidos por Auler et al. (2004), em experimento conduzido no noroeste do Paraná, em copa de laranjeira 'Valência', onde 'Sunki' se destacou com a maior produção de frutos entre os porta-enxertos avaliados, sendo equivalente à 'Cleópatra', porém sem diferir do 'Cravo'. Está de acordo também com os obtidos por Stuchi et al. (2002), ao verificarem que 'Sunki' e 'Cleópatra' induziram maiores produções de frutos em laranja 'Valência', diferindo de 'Troyer' e de outros porta-enxertos avaliados, onde não estava incluído o 'Cravo'.

Resultados discordantes dos aqui obtidos foram observados em outras regiões produtoras, nos quais também foi incluído na avaliação o limoeiro 'Cravo', que sempre aparece liderando a produção de frutos em laranjeira 'Valência', como observado por Roberto et al. (1999), com maior média de produção nas três primeiras safras, superando inclusive a 'Sunki'. Da mesma forma, Pompeu Jr. (1981) verificou que os porta-enxertos 'Cravo' e 'Orlando' apresentaram médias de produção superiores à 'Sunki' e 'Cleópatra', em dez safras avaliadas, e Ledo et al. (1999) observaram que o 'Cravo' foi superior à 'Sunki' e equivalente à 'Cleópatra' e ao citrangeiro 'Carrizo' nos quatro primeiros anos de produção. Cabe ressaltar que esses trabalhos foram conduzidos em regiões com condições edafoclimáticas diferentes, com clima caracterizado por estação seca mais definida e acentuada do que as condições encontradas no presente trabalho e, provavelmente, esse seja o principal fator envolvido nas diferenças observadas, tanto para a produção como para o desenvolvimento vegetativo. De fato, por sua maior resistência à seca, o limoeiro 'Cravo' tende a apresentar melhores resultados em condições onde a deficiência hídrica é mais acentuada (Pompeu Jr., 2005).

Pela Tabela 3, é possível observar-se uma alternância de safra, caracterizada pela redução da produção de frutas em um ano, em decorrência da alta produção anterior, em todos os portaenxertos utilizados. De acordo com Medina et al. (2006), essa alternância é freqüente em laranjeiras Valência e Hamlim e em tangerineiras e híbridos como o Murcott, sendo observada redução de 20 a $80 \%$ na produção.

Registrou-se para a laranjeira 'Valência', enxertada em tangerina 'Cleópatra', baixa produção nos dois primeiros anos de avaliação (tabela 3). Segundo Pompeu Jr. (2005), uma das inconveniências do uso da 'Cleópatra' como porta-enxerto é iniciar sua produção mais tardiamente. No entanto, verificou-se que, a partir da $3^{\text {a }}$ safra, seu desempenho figurou entre os de maior produção, juntamente com a tangerineira 'Sunki' e o tangeleiro 'Orlando', contrariando as referências de que este porta-enxerto requer vários anos para consolidar seus níveis produtivos (Bravo \& Gallardo, 1994b; Zekri \& Al-Jaleel, 2004; Zekri, 2000).

Por sua vez, os dados referentes à eficiência de produção indicam que, em 1999, o 'Troyer' foi superior ao 'Orlando', e estes não diferiram dos demais e, em 2003, 'Cravo', 'Sunki' e 'Troyer' não diferiram entre si e apresentaram melhor eficiência em relação aos demais porta-enxertos (Tabela 4). O tangeleiro 'Orlando', que figura entre os porta-enxertos com maior produção por planta, teve o pior desempenho na relação entre produção/ volume de copa, nos dois anos avaliados.

Porta-enxertos que induzam à copa eficiência de produção superior ou equivalente e que apresentem menor volume de copa, podem ser tão ou mais interessantes que aqueles com maior volume de copa e com maior produção de fruto por planta, pois indicam que essa produção pode ser compensada com o aumento da densidade de plantas por área, como é o caso, no presente estudo, de 'Troyer' e do próprio 'Cravo' em relação à 'Sunki' e à 'Cleópatra' (Tabelas 2 e 4). Entretanto, cabe ressaltar que, no cálculo do volume de copa, o diâmetro é o componente de maior influência e o parâmetro efetivamente utilizado na definição do espaçamento e que, embora tenham ocorrido diferenças significativas entre os diâmetros de copa induzidos pelos portaenxertos (Tabela 2), a pequena magnitude dessas diferenças limitam um pouco o uso do adensamento para compensar menor produção.

Atualmente, tem crescido o interesse em se utilizarem porta-enxertos que induzam copa menor, com alta eficiência produtiva em relação ao seu volume, característica que permite bons níveis de produtividade com o aumento da densidade de plantas por área (Donadio et al., 1995), e também redução nos 
custos de colheita e melhoria na eficiência dos tratos fitossanitários (Pompeu Jr., 2001). Por outro lado, deve-se levar em conta a maior demanda hídrica e por nutrientes com o uso do adensamento.

Em avaliação realizada aos 12 anos após o plantio, não foi constatada mortalidade de plantas ou sintomas visuais na parte aérea que pudessem indicar algum problema que afeta a combinação copa/porta-enxerto, como, por exemplo, a ocorrência de declínio, tendo elas apresentado um índice de $100 \%$ de sobrevivência, em todos os porta-enxertos avaliados.

Dentro das condições edafoclimáticas caracterizadas no presente estudo, os resultados indicam que existem opções para diversificação de porta-enxertos ao limoeiro 'Cravo' para cultivo da laranjeira 'Valência', na região noroeste do Paraná. A tangerineira 'Sunki' superou o 'Cravo' em produção e apresentou eficiência de produção equivalente a esse porta-enxerto, despontando como opção para a produção da laranjeira 'Valência' destinada tanto ao mercado de fruta fresca como à indústria. A 'Cleópatra' também se destacou por apresentar produção e qualidade de frutos equivalentes ao 'Cravo'. A principal desvantagem dessas tangerineiras em relação ao 'Cravo' foi o seu maior volume de copa, exigindo maiores espaçamentos. Merece destaque, também, o citrangeiro 'Troyer', pois apresentou eficiência de produção equivalente e rendimento industrial superior ao 'Cravo', fatos que, aliados ao aspecto econômico envolvendo possíveis menores custos com tratos culturais e colheita, devido ao seu porte mais reduzido, colocamno como uma potencial opção de porta-enxerto para a laranjeira 'Valência'. Nesse caso, destinada principalmente à indústria, em função do menor peso médio dos frutos.

TABELA 1 - Características de qualidade do fruto e rendimento industrial de laranjeira 'Valência' sobre seis porta-enxertos, média das avaliações de 2002 e 2005, Nova Esperança-PR.

\begin{tabular}{|c|c|c|c|c|c|c|c|c|c|c|c|c|}
\hline \multirow{2}{*}{$\begin{array}{l}\text { Porta-enxertos } \\
\text { Limoeiro 'Cravo' }\end{array}$} & \multicolumn{2}{|c|}{$\begin{array}{l}\text { Massa média } \\
\text { dos frutos }^{(1)} \\
\text { (g) }\end{array}$} & \multicolumn{2}{|c|}{$\begin{array}{c}\text { Rendimento em } \\
\text { suco } \\
(\%)\end{array}$} & \multicolumn{2}{|c|}{$\begin{array}{c}\text { Sólidos solúveis } \\
\text { totais (SST) } \\
\left({ }^{\circ} \text { Brix) }\right.\end{array}$} & \multicolumn{2}{|c|}{$\begin{array}{c}\text { Acidez titulável } \\
\text { total (ATT) } \\
\text { (\% ácido cítrico) }\end{array}$} & \multicolumn{2}{|c|}{$\begin{array}{c}\text { Ratio } \\
\text { (SST/ATT) }\end{array}$} & \multicolumn{2}{|c|}{$\begin{array}{c}\text { Rendimento } \\
\text { industrial } \\
\text { (Caixa } \mathbf{t}^{-1} \text { suco) }\end{array}$} \\
\hline & $182,0^{(2)}$ & $\mathrm{a}$ & 52,1 & $\mathrm{a}$ & 10,4 & $\mathrm{c}$ & 0,8 & $\mathrm{a}$ & 13,4 & $\mathrm{a}$ & 298,1 & $\mathrm{a}$ \\
\hline Tangerineira 'Cleópatra' & 177,2 & $a b$ & 52,7 & a & 10,9 & abc & 0,8 & $\mathrm{a}$ & 13,0 & $\mathrm{a}$ & 281,3 & $a b$ \\
\hline Tangerineira 'Sunki' & 176,2 & $\mathrm{ab}$ & 52,1 & a & 11,3 & abc & 0,9 & $\mathrm{a}$ & 12,5 & a & 276,1 & $\mathrm{ab}$ \\
\hline Citrangeiro 'Troyer' & 164,2 & $\mathrm{~b}$ & 51,9 & a & 11,9 & a & 0,9 & $\mathrm{a}$ & 13,8 & $\mathrm{a}$ & 268,6 & $\mathrm{~b}$ \\
\hline Tangeleiro 'Orlando' & 183,7 & $\mathrm{a}$ & 51,4 & a & 10,8 & bc & 0,8 & $\mathrm{a}$ & 13,7 & a & 293,9 & $a b$ \\
\hline Laranjeira 'Caipira' & 180,0 & $\mathrm{a}$ & 50,3 & a & 11,5 & $a b$ & 0,9 & $\mathrm{a}$ & 12,5 & $\mathrm{a}$ & 280,6 & $\mathrm{ab}$ \\
\hline CV (\%) & 3,7 & & 2,2 & & 3,9 & & 10,7 & & 10,9 & & 4,3 & \\
\hline
\end{tabular}

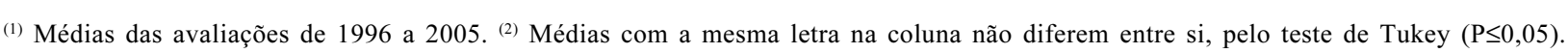

TABELA 2- Altura da planta, diâmetro e volume da copa de laranjeira 'Valência' sobre seis porta-enxertos, Nova Esperança-PR.

\begin{tabular}{|c|c|c|c|c|c|c|c|c|c|c|c|c|}
\hline \multirow{3}{*}{$\begin{array}{l}\text { Porta-enxertos } \\
\text { Limoeiro 'Cravo' }\end{array}$} & \multicolumn{4}{|c|}{$\begin{array}{c}\text { Altura da planta } \\
\text { (m) }\end{array}$} & \multicolumn{4}{|c|}{$\begin{array}{c}\text { Diâmetro da copa } \\
\text { (m) }\end{array}$} & \multicolumn{4}{|c|}{$\begin{array}{c}\text { Volume da copa } \\
\qquad\left(\mathrm{m}^{3}\right)\end{array}$} \\
\hline & \multicolumn{2}{|c|}{1999} & \multicolumn{2}{|c|}{2003} & \multicolumn{2}{|c|}{1999} & \multicolumn{2}{|c|}{2003} & \multicolumn{2}{|c|}{1999} & \multicolumn{2}{|c|}{2003} \\
\hline & $3,0^{(1)}$ & abc & 3,2 & $\mathrm{c}$ & 3,2 & $\mathrm{~b}$ & 3,7 & bcd & 16,7 & $\mathrm{bc}$ & 23,7 & $\mathrm{~b}$ \\
\hline Tangerineira 'Cleópatra' & 3,3 & $\mathrm{a}$ & 3,9 & a & 3,6 & a & 4,1 & $\mathrm{ab}$ & 22,0 & a & 34,3 & a \\
\hline Tangerineira 'Sunki' & 3,3 & $\mathrm{a}$ & 3,9 & $\mathrm{a}$ & 3,4 & $\mathrm{ab}$ & 4,0 & $\mathrm{bc}$ & 20,7 & $a b$ & 32,4 & $\mathrm{a}$ \\
\hline Citrangeiro 'Troyer' & 2,7 & $\mathrm{c}$ & 3,1 & $\mathrm{c}$ & 2,9 & $\mathrm{c}$ & 3,6 & $\mathrm{~cd}$ & 12,1 & d & 21,9 & $\mathrm{~b}$ \\
\hline Tangeleiro 'Orlando' & 3,2 & $\mathrm{ab}$ & 3,8 & $a b$ & 3,5 & $\mathrm{ab}$ & 4,2 & $\mathrm{a}$ & 21,1 & $a b$ & 35,3 & $\mathrm{a}$ \\
\hline Laranjeira 'Caipira' & 2,9 & $\mathrm{bc}$ & 3,4 & $\mathrm{bc}$ & 2,9 & $\mathrm{c}$ & 3,5 & $d$ & 12,3 & $\mathrm{~cd}$ & 22,4 & $\mathrm{~b}$ \\
\hline CV (\%) & 5,6 & & 4,8 & & 4,3 & & 4,7 & & 11,2 & & 11,8 & \\
\hline
\end{tabular}

(1) Médias com a mesma letra na coluna não diferem entre si, pelo teste de Tukey $(\mathrm{P} \leq 0,05)$. 
TABELA 3 - Produção média anual (kg/planta) das safras de 1996 a 2005 de laranjeiras 'Valência' sobre seis porta-enxertos, NovaEsperança-PR.

\begin{tabular}{|c|c|c|c|c|c|c|c|c|c|c|c|c|c|c|c|c|c|c|c|c|}
\hline \multirow{2}{*}{$\begin{array}{l}\text { Porta-enxertos } \\
\text { L. 'Cravo' }\end{array}$} & \multicolumn{2}{|c|}{$1996^{(2)}$} & \multicolumn{2}{|c|}{1997} & \multicolumn{2}{|c|}{1998} & \multicolumn{2}{|c|}{1999} & \multicolumn{2}{|c|}{2000} & \multicolumn{2}{|c|}{2001} & \multicolumn{2}{|c|}{2002} & \multicolumn{2}{|c|}{2003} & \multicolumn{2}{|c|}{2004} & \multicolumn{2}{|c|}{2005} \\
\hline & $11,1^{(1)}$ & $\bar{a}$ & 60,6 & $\mathrm{ab}$ & 39,0 & $\mathrm{ab}$ & 90,2 & bcd & 88,3 & $\mathrm{bc}$ & 57,0 & $\mathrm{a}$ & 173,4 & $\mathrm{abc}$ & 103,3 & $\mathrm{ab}$ & 129,1 & $\mathrm{a}$ & 115,1 & $\mathrm{bc}$ \\
\hline T. 'Cleópatra' & 1,0 & $\mathrm{c}$ & 43,2 & $\mathrm{bc}$ & 49,4 & $\mathrm{a}$ & 117,8 & $\mathrm{ab}$ & 176,2 & $\mathrm{a}$ & 57,9 & $\mathrm{a}$ & 171,4 & $a b c$ & 148,2 & $\mathrm{a}$ & 103,1 & $\mathrm{a}$ & 192,3 & $\mathrm{a}$ \\
\hline T. 'Sunki' & 3,8 & bc & 74,4 & $\mathrm{a}$ & 48,4 & $\mathrm{ab}$ & 123,3 & a & 172,4 & a & 53,6 & $\mathrm{a}$ & 203,4 & $a b$ & 146,1 & $\mathrm{a}$ & 130,8 & $\mathrm{a}$ & 178,2 & $a b$ \\
\hline C. 'Troyer' & 8,0 & $a b$ & 45,7 & $\mathrm{bc}$ & 42,3 & $a b$ & 73,7 & $\mathrm{~cd}$ & 105,4 & $\mathrm{bc}$ & 29,2 & $\mathrm{a}$ & 148,7 & $\mathrm{c}$ & 103,1 & $a b$ & 99,8 & a & 114,7 & $\mathrm{bc}$ \\
\hline T. 'Orlando' & 3,4 & bc & 48,2 & $\mathrm{bc}$ & 31,6 & $\mathrm{ab}$ & 102,6 & $a b c$ & 133,7 & $\mathrm{ab}$ & 48,6 & $\mathrm{a}$ & 205,8 & $\mathrm{a}$ & 98,9 & $a b$ & 125,6 & $\mathrm{a}$ & 149,7 & $a b c$ \\
\hline L. 'Caipira' & 7,6 & $\mathrm{ab}$ & 32,2 & $\mathrm{c}$ & 28,1 & $\mathrm{~b}$ & 70,3 & d & 76,9 & $\mathrm{c}$ & 28,6 & $\mathrm{a}$ & 153,3 & bc & 75,5 & $\mathrm{~b}$ & 87,2 & $\mathrm{a}$ & 99,5 & $\mathrm{c}$ \\
\hline CV(\%) & 16 , & & 15 & & 22 & & 14 & & 17, & & 29 , & & 12 & & 25 , & & 39,9 & & 21 & \\
\hline
\end{tabular}

(1) Médias com a mesma letra na coluna não diferem entre si, pelo teste de Tukey $(\mathrm{P} \leq 0,05)$. (2) Dados transformados em $\sqrt{x+1}$.

TABELA 4 - Produção acumulada e relativa ao limoeiro 'Cravo' de frutos das dez primeiras safras e eficiência de produção de laranjeira 'Valência' sobre seis portaenxertos, Nova-Esperança-PR.

\begin{tabular}{|c|c|c|c|c|c|c|}
\hline \multirow{3}{*}{ Porta-enxertos } & \multirow{3}{*}{$\begin{array}{l}\text { Produção acumulada } \\
\qquad\left(\text { kg planta }^{-1}\right)\end{array}$} & \multirow{3}{*}{$\begin{array}{l}\text { Produção acumulada } \\
\text { relativa (\%) }\end{array}$} & \multirow{2}{*}{\multicolumn{4}{|c|}{$\begin{array}{l}\text { Eficiência da produção } \\
\qquad\left(\mathrm{kg} \mathrm{m}^{-3}\right)\end{array}$}} \\
\hline & & & & & & \\
\hline & & & \multicolumn{2}{|l|}{1999} & \multicolumn{2}{|c|}{2003} \\
\hline Limoeiro 'Cravo' & $867,7^{1}$ bcd & 100 & 5,4 & $\mathrm{ab}$ & & $\mathrm{a}$ \\
\hline Tangerineira 'Cleópatra' & $1061,3 \quad a b$ & 122,3 & 5,4 & $a b$ & 4,1 & $\mathrm{~b}$ \\
\hline Tangerineira 'Sunki' & $1134,8 \quad a$ & 130,8 & 6,0 & $a b$ & 4,5 & $\mathrm{a}$ \\
\hline Citrangeiro ‘Troyer' & 770,9 cd & 88,8 & 6,2 & a & 4,8 & $\mathrm{a}$ \\
\hline Tangeleiro 'Orlando' & $948,4 \quad a b c$ & 109,3 & 4,9 & $b$ & 3,5 & $\mathrm{c}$ \\
\hline Laranjeira 'Caipira' & $660,9 \mathrm{~d}$ & 76,2 & 5,7 & $a b$ & 4,1 & $\mathrm{~b}$ \\
\hline $\mathrm{CV}(\%)$ & 10,4 & & 9,3 & & 4,0 & \\
\hline
\end{tabular}

${ }^{1}$ Médias com a mesma letra na coluna não diferem entre si, pelo teste de Tukey $(\mathrm{P} \leq 0,05)$.

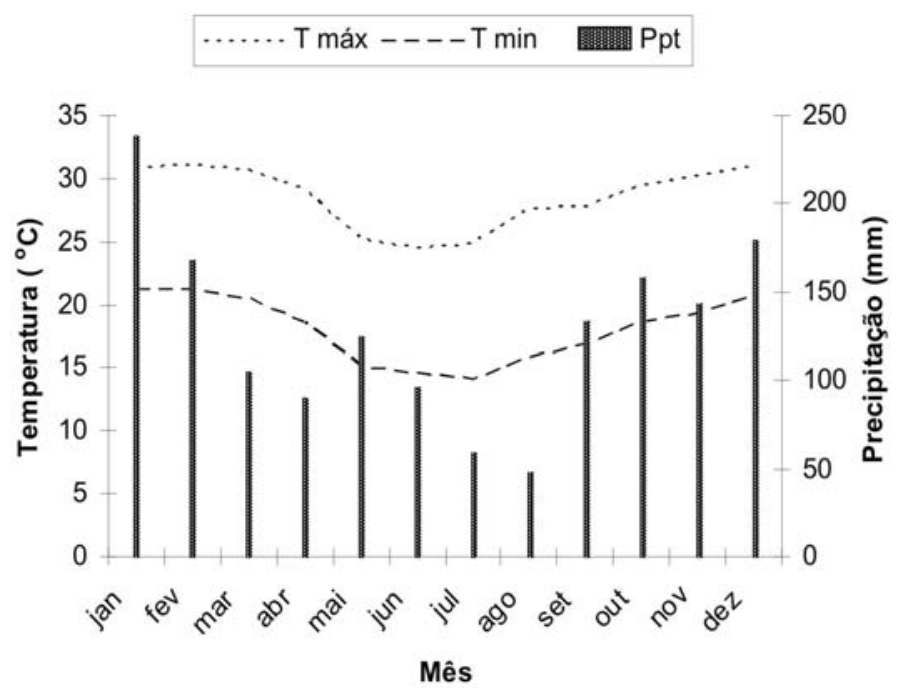

Fonte: Sudersha,2006.

FIGURA1 - Precipitação pluvial (Ppt) e temperatura do ar, máxima (T máx) e mínima (T mín), médias mensais no periodo de 1994 a 2005. Nova Esperança-PR.

\section{CONCLUSÃO}

Dentre os porta-enxertos avaliados, as tangerineiras 'Sunki' e 'Cleópatra', e o citrangeiro 'Troyer' destacam-se como alternativas ao uso do limoeiro 'Cravo' como porta-enxerto para laranjeira 'Valência', na região noroeste do Paraná.

\section{AGRADECIMENTOS}

Aos citricultores Gilberto e Antônio Pratinha, pela cessão da área experimental e apoio na condução do experimento.

\section{REFERÊNCIAS}

AOAC - ASSOCIATION OF OFFICIAL ANALYTICAL CHEMISTS. Official methods of analysis. $15^{\text {th }}$ ed. Arlington: AOAC, 1990. 1298p.

AULER. P.A.M.; FIDASLKI, J.; PAVAN, M. A.; GOMES, J. C.; JACOMINO, A. P. Sistemas de preparo do solo, calagem e portaenxertos para a produção de laranja Valência na região noroeste do Paraná. In: CONGRESSO BRASILEIRO DE FRUTICULTURA, 18., 2004, Florianópolis. Anais... Florianópolis: SBF, 2004. CDROM.

BRAVO, I.M.; GALLARDO, E. Comportamiento del naranjo 'valencia'sobre trece patrones em Lara, Venezuela I. Crecimento. Agronomia Tropical, Maracay, v.44, n.4, p.619-628, 1994a.

BRAVO, I.M.; GALLARDO, E. Comportamiento del naranjo 'valencia' sobre trece patrones em Lara, Venezuela II. Producion y calidade de fruta. Agronomia Tropical, Maracay, v.44, n.4, p.629643, 1994b.

CARLOS, E. F.; STUCHI, E.S.; DONADIO, L.C. Porta-enxertos para a citricultura paulista. Jaboticabal: Funep, 1997. 47p. (Boletim Citrícola, 1).

COELHO, Y.S. Frutas cítricas importadas no mercado de Salvador, Bahia. Bahia Agrícola, Salvador, v.5, n.2, p.29-33, 2002. 
DONADIO, L.C.; CABRITA, J.R.M.; SEMPIONATO, O.R.; PARO, M. Tangerineira Cleópatra: vantagens e desvantagens como porta-enxerto na citricultura. Laranja, Cordeirópolis, v.14, n.2, p. 565-579, 1993.

DONADIO, L.C.; ROBERTO, S.R.; SEMPRIONATO, O.R. Adensamento tem custo de implantação maior, mas é mais econômico. Informativo Coopercitrus, Bebedouro, n.102, p.24, 1995.

IBGE. Instituto Brasileiro de Geografia e Estatística. Disponível em: $<$ http:/www.ibge.gov.br $>$. Acesso em : 15 out. 2004.

IAPAR. INSTITUTO AGRONÔMICO DO PARANÁ. A citricultura no Paraná. Londrina, 1992. 288p. (Circular, 72).

LEDO, A.S.; LEDO, F.J.S.; RITZINGER, R.; CUNHA SOBRINHO, A.P. Porta-enxertos para laranjeiras-doces (Citrus sinensis (L.) Osb.) em Rio Branco, Acre. Pesquisa Agropecuária Brasileira, Brasília, v.34, n.7, p. 1211-1216, 1999.

MEDINA, C.L.; PRADO, A.K.S.; MACHADO, E.C. Nutrição e alternância de safra nos citros. Citricultura atual, Cordeirópolis, n.53, p.4-5, 2006.

MENDEL, K. Rootstock-scion relationships in Shamouti trees on light soil. Ktavim, Rehovot, v.6, p.35-60, 1956.

MÜLLER, G.M.; TARGON, M.L.P.N.; CARVALHO, S.A.; SOUZA, A.A.; RODRIGUES, J. C.V. Doenças de citros causadas por vírus e viróides. In: MATTOS JUNIOR, D.; PIO, R.M.; DE NEGRI, J.D.; POMPEU JR., J. (Ed.). Citros. Campinas: Instituto Agronômico e Fundag, 2005. p.567-604.

POMPEU JR., J. Comportamento da laranjeira Valência Citrus Sinensis (L.) Osbeck, em 18 porta-enxertos. In: CONGRESSO BRASILEIRO DE FRUTICULTURA, 6., Recife, 1981. Anais... Recife: SBF, 1981.p. 530-541.

POMPEU JR., J. Porta-enxertos para citros potencialmente ananicantes. Laranja, Cordeirópolis, v.22, n.1, p.147-155, 2001.
POMPEU JR., J.; LARANJEIRA, F.F.; BLUMER, S. Laranjeiras 'Valência' enxertadas em híbridos de trifoliata. Scientia Agrícola, Piracicaba, v.59, n.1, p.93-97, 2002.

POMPEU JR., J. Porta-enxertos. In: MATTOS JR., D.; DE NEGRI, J.D.; PIO, R.M.; POMPEU JR., J. Citros. Campinas: Instituto Agronômico e Fundag, 2005. p. 63-94.

ROBERTO, S.R.; LIMA, J.E.; CARLOS, E.F. Produtividade inicial da laranjeira 'Valência'(Citrus sinensis L. Osbeck) sobre oito porta-enxertos no Estado de São Paulo. Revista Brasileira de Fruticultura, Jaboticabal, v.21, n.2, p.119-122, 1999.

SARTORI, I.A.; SCHÄFER, G.; PANZENHAGEN, N.V.; KOLLER, O.C.; SCHWARZ, S.F. Comportamento da laranjeira 'Valência (Citrus sinensis (L.) Osb.) em oito porta-enxertos. In: CONGRESSO BRASILEIRO DE FRUTICULTURA, 17., 2002, Belém. Anais... Belém: SBF, 2002.CD-ROM

SCHÄFER, G.; BASTIANEL, M.; DORNELLS, A.L.C. Portaenxertos utilizados na citricultura. Ciência Rural, Santa Maria, v.31, n.4, p.723-733, 2001.

STENZEL, N.M.C.; NEVES, C.S.V.J.; SCHOLZ, M.B.S.; GOMES, J.C. Comportamento da laranjeira 'Folha Murcha'em sete portaenxertos no noroeste do Paraná. Revista Brasileira de Fruticultura, Jaboticabal, v.27, n.3, p.408-411, 2005.

STUCHI, E.S.; DONADIO, L.C.; SEMPIONATO, O.R. Qualidade industrial e produção de frutos de laranjeira 'Valência' enxertada sobre sete porta-enxertos. Laranja, Cordeirópolis, v.23, n.2., p.453-471, 2002.

ZEKRI, M. Evaluation of orange trees budded on several rootstocks and planted at high density on flatwoods soil. Proceedings of Florida State Horticultural Society, Gainesville, v.113, p.119-123, 2000.

ZEKRI, M.; AL-JALEEL, A. Evaluation of rootstocks for Valencia and Navel orange trees in Saudi Arábia. Fruits, Les Ulis Cedex, v.59, n.2, p.91-100, 2004. 